\section{Dr.Assrar Sabry}

Business Administration

Lecturer

Alexandria University

Faculty of Commerce

\section{The Impact of Manufacturing} Strategy Dimensions on JIT Practices in Some of the Egyptian Companies

\section{Abstract}

Just-in-Time (JIT) practices have long been, and continue to be, a topic of great interest in the literature and practice of operations strategy and the link between manufacturing strategies remains incomplete. This research aims to examine the impact of four dimensions of the manufacturing strategy namely, achievement of functional integration, formal planning of manufacturing strategy, the link between manufacturing strategy and business strategy, and the anticipation of new technology and three JIT practices: the setup time reduction, the use of Kanban system, and the daily schedule adherence. Data were collected through a questionnaire on a sample of 25 Egyptian industrial companies from 233 managers with a response rate of $82.40 \%$.The statistical methods; factor analysis, descriptive analysis, and multiple regressions were applied to examine four hypotheses.The results revealed that not all the hypotheses were supported. Implications for theory and practice were discussed and possible directions for future research are presented.

Keywords:Manufacturing Strategy Dimensions MSD, Just in Time JIT, Achievement of Functional Integration AFI, Formal planning of manufacturing strategy FPMS

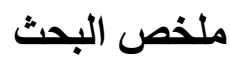

تسعي الدراسة الحالية إلى التعرف على تأثير أربعة أبعاد

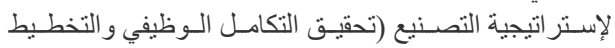

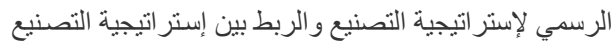

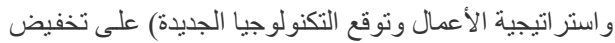

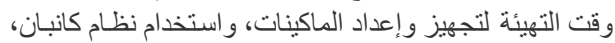
و الالتز ام بجدول الإنتاج اليومي باعتبار هم أكثر الممارسات

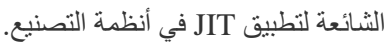

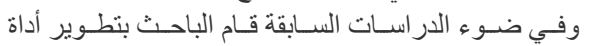

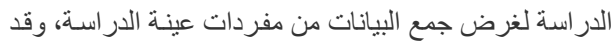

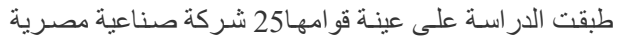

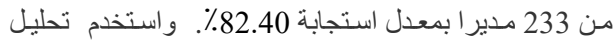

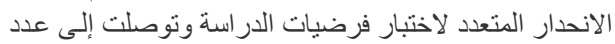

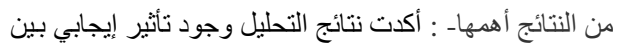

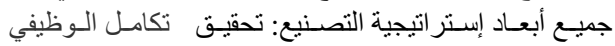

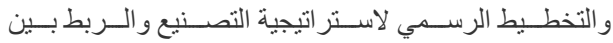

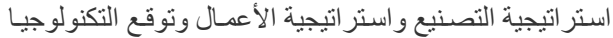

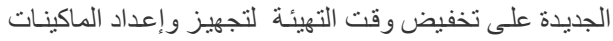

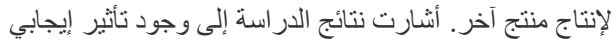

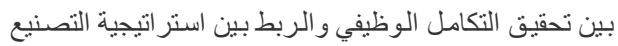

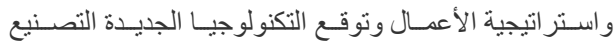
باستثناء التخطيط الرسمي لإستر اتيجية التصنيع على التئ استخدام

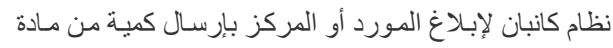

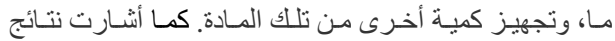
التحليل تحقيق التكامل الوظيفي واستباق التكنولوجيا لونيا الجديدة

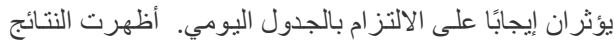
أنه لم يتم دعم جميع الفرضيات.

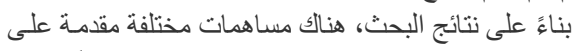

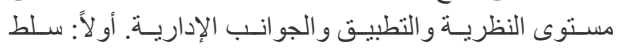

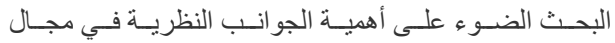

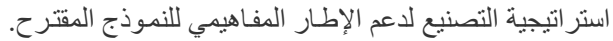

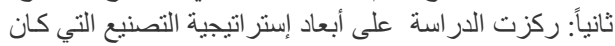

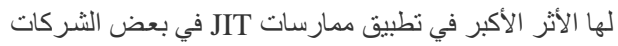

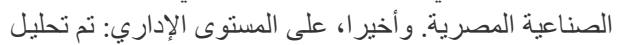

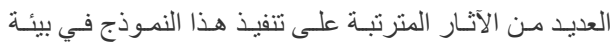

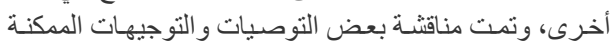

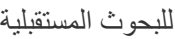




\section{Introduction}

The management literature ignored the importance of manufacturing strategy and it has begun to gain the attention of researchers after the work provided by Skinner in 1969 (Ocampo and Clark 2015). MS became a part of a company's strategy and it has its effect on the pattern of taking the strategic decisions, and the actions required for realizing the plant's objectives in the industrial companies (Jia and Bai 2011). During the last two decades, large number of researchers concentrated on exploring the content of the manufacturing strategy and a few studies focused on investigating the dimensions of manufacturing strategy (Löf-ving, Säfsten, and Winroth 2014). Abdallah and Matsui (2007) mentioned that the relationship between JIT practices and MS is rarely debated in the literature and there were two studies only made by (Sakakibara, Flynn, Schroeder, and Morris 1997; Ahmad, Schroeder, and Sinha 2003). Moreira and Alves (2008) stated that several studies have been conducted in some of developed countries such as United States, United Kingdom, Japan, and Canada. Later other studies have been conducted in some developing countries such as Mexico, Egypt, Ghana, India, Malaysia, Jordan, and Saudi Arabia. However, compared to other parts of the world, the empirical studies are considered very limited particularly in Egypt (Salaheldin 2005; Hashim 2010). Manufacturing companies are searching for new ways to optimize their manufacturing practices in today's fast changing market and found that manufacturing function has been changed because of it's influenced by adopting new philosophy called JIT (Chen and Tan 2013 ; Khaireddin, Abu
Assab, and Nawaf-leh 2015; Patil, Narkhede, and Akarte 2012a,2016b; Phogat and Gupta 2017). In many of the aforementioned studies, the relationship between MSD and JIT practices have not received much attention in manufacturing strategy research.This supports the need for further testing and replication the research in the field of manufacturing strategy (Grant 2013) .This gap in the literature is more profound in Egypt.The current research intends to rely on contingent perspective to provide a finer-grained understanding of MSD taken into consideration their impact on JIT practices. MSD are hypothesized as an integration of four dimensions of manufacturing strategy, namely, achievement of functional integration, formal planning of manufacturing strategy, the linkage between manufacturing and business strategy and anticipating of new technology to highlight their impact on JIT practices in some Egyptian manufacturing companies. For this, this research seeks to answer the following questions:

1-Do the manufacturing strategy dimensions significantly impact on set uptime reductions in the research sample?

2-Do the manufacturing strategy dimensions significantly impact on using the kanban system in the research sample?

3-Do the manufacturing strategy dimensions significantly impact on the adherence of the daily schedule in the research sample?

The following section will provide the literature review on the conceptualizations of both of the MSD and JIT, prior that studied the link between each of the four MSD and JIT practices. 
This is followed by a description of the research methodology, data analysis and the discussion of the research results. The current research concludes the implications for managers and the directions for future research.

\section{Literature Review}

Since early 1980, some practitioners and researchers such as (Sakakibara et al. 1997; Ahmad et al. 2003; Phan and Matsui 2006; Hashim 2010; Hou, Chan, and Wang 2011; Yuan 2015; Al Haraisa 2017) discussed the importance of JIT practices as a powerful tool to achieve the continuous improvement in all phases of manufacturing processes.

\subsection{Conceptualization of the Manufacturing Strategy Dimensions}

Based on an extensive review of MS, pioneer scholars defined it with some variations (Aboutalebi 2016). For example, MS is defined from the production perspective as a function to create a competitive advantage (Skinner 1969). Hill (1989) believed that it is a systematic process required for supporting production departments to achieve higher performance. The work provided by McGrath and Hoole (1992) revealed that there was no formal MS at all; only a series of manufacturing decisions made at different times and found a poor match between MS and business strategy. Prior researches such as (Schroeder et al. 1986; Miller and Hayslip 1989) focused on developing the link between corporate, manufacturing and business strategies to achieve the corporate objectives (Jia et al. 2011; Wang, Chen, and Wang 2016). The review of the extant literature on
MSD pointed out the most common dimensions in the absence of clear universal determinants (Grant 2013). Aboutalebi (2016) reported that less number of relevant publications regarding MSD has been made in recent time. For example, Ahmad et al. (2003) suggested four MSD namely, MS strength, communication of manufacturing strategy, formal planning of manufacturing strategy, and the link between manufacturing and business strategy.Dangayach and Deshmukh (2004a, 2006b) suggested four dimensions namely, functional integration of manufacturing, formal planning alignment of manufacturing with business units, communication of MS and developing proprietary of manufacturing equipment. Abdallah et al. (2007), Nayebzadeh (2010) and Garrido-Vega, Ortega Jimenez,Díez Pérez, and Morita (2015) are consistent in four MS dimensions namely, anticipating new technology, the link between manufacturing and business strategy, formal planning of manufacturing strategy and the communicating with manufacturing strategy, except for proprietary equipment, and achievement of functional integration. While, the work of Thun (2008) focused on the integration between manufacturing strategy dimensions and supported the link between MS and business strategy of the corporation. Amoako-Gyampah and Acquaah (2008) and Patil et al. (2012a, 2016b) suggested four dimensions namely, competitive force to manufacturing strategy, functional integration, formal planning of manufacturing strategy, communication with manufacturing strategy, and integrating manufacturing strategy within business strategy. However, the finding from Abdallah et al. (2007) 
posited that formal planning of manufacturing strategy is considered as one of the important dimension to measure MSD.The results of Ocampo et al. (2015) are consistent with the findings of Dombrowski, Intra, Zahn, and $\mathrm{Kr}$ enkel (2016) and Shavarini, Salimian, Nazemi, and Alborzi (2013) to support the role of plant manager in preparing the formal manufacturing plan to be consistent with the corporate strategy, to be aware of $\mathrm{MS}$, and to facilitate translating it into the manufacturing strategy. Meanwhile, few researches such as (e.g., Pisano 1996; Pun 2004; Hallgren and Olhager 2006) studied the influence of MS on achieving the objectives of both of the corporate strategy and the other functional divisions.

The review of the extant literature on anticipating new technology as one of MSD, Saukkonen, Vasamo, Ballard, and Levie (2016) concluded that anticipating technology as a strategic action was started in the 1960 by large corporations in the field of technology such as Motorola company. Matsui (2002) found manufacturing strategies have positive and significant impact on developing new technologies. Hallgren (2007) is consistent with Ward et al. (1996) who concluded that MS can assist the plant manager to understand the manufacturing capabilities and to determine the essential investments matching with the corporate objectives. Finger, Flynn, and Paiva (2014) found a significant impact of anticipating new technology on the firm's ability to provide its manufacturing needs in advance and to think of the next generation of manufacturing technology. Saukkonen et al. (2016) stated that today, the industrial companies are for- ced to re-examine their process for improving product quality and reducing the cost of production faster than their competitors by adopting new manufacturing technology. Adopting JIT manufacturing and integrating the manufacturing strategies can improve the operational performance (Fullerton and McWatters 2001; Singh and Ahuja 2012).

\subsection{Conceptualization of JIT Practices}

From a theoretical perspective, Monden (1981) was the first who provided a thorough overview of JIT philosophy including Kanban system, and setup time reduction (Ahmed et al. 2003). While, Singh and Ahuja (2014) reported that JIT started by Bicheno (1987) who defined it as a system of production control for achieving perfection in a manufacturing system. JIT manufacturing has become one of the most research topics in the area of operations management and there is different conceptuality in the extant literature (Mackelprang and Nair 2010). For example, Upton (1998) defined JIT as a managerial philosophy, while other researchers such as (Flynn, Sakakibara, and Schroeder 1995; Shah and Ward 2003) defined JIT as a set of practices that should be used in manufacturing systems to improve the processes. Egyptian manufacturing companies consider JIT as a strategic philosophy, not as a temporary solution for dealing with the operational problems (Hashim 2010). JIT is considered the lost time between the productions of the last item until the production of the new item is made (Fateha, Nafrizuan, and Razlan 2012). JIT is a philosophy of manufacturing that helps to eliminate both of the waste-over production, in- 
effective processing, and to reduce the setup time (Chen et al. 2013; Van Wyk and Naidoo 2016).

Prior researchers argued the key elements that needed to implement JIT practices in manufacturing system. Sakakibara, Flynn, and Schroeder (1993) suggested layout of equipment, producing based on a pull system, and a Kanban system. Flynn, Schroeder, Flynn, Sakakibara, and Bates (1997) linked between a kanban system, JIT scheduling and manufacturing performance. Meanwhile, Swink, Narasimhan, and Kim (2005) concluded several key elements of JIT practices that reported in many researches. For instance, small lot size, production scheduling, and setup time reduction (Flynn et al. 1995); lot size, setup time reduction, and production flow (Shah et al. 2003). Kootanaee, Babu, and Talari (2013) reported that the prime motivating factor for the plant managers is to avoid delays in the production schedule, and to use a Kanban system in order to link the different production processes together. Obamiro (2009) found positive relationship between production schedule, and manufacturing performance. Cua, McKone, and Schroeder (2001) found positive relationship between reducing setup times, adherence of daily schedule and time needed to deliver quality products to customers. Ahmad, Mehra, and Pletcher (2002) found positive relationship between production strategy, setup time reduction, and Kanban system. Results of Shah et al. (2003) found significant positive relationship between operational performance at the level of the plants and Kanban system, scheduling planning. Abdallah et al. (2007) investigated the impact of MSD on production scheduling, and reducing setup times. Diaz and Ardalan (2010) showed that production systems have significant and positive relationship with the average of setup times per operation and a kanban system has the highest significant impact on the stability of the master production schedule. Khaireddin et al. (2015) found positive impact of improving strategic performance and adherence of daily schedule, layout of equipment, and reducing setup time. The results of AZu'bi (2015) showed setup time reduction explained $(59.64 \%)$ of the variance for improving flexibility of plant performance. According to Singh et al. (2012) reducing setup times, using Kanban system, and eliminating equipment downtime should be enough to ensure the stability of production schedule. Mackelprang et al. (2010) concluded the most JIT practices widely used in some of previous literature (e.g., Flynn et al. 1995a, 1997b; Fullerton et al. (2001); Challis et al. (2005); Matsui 2007) namely reduction setup times, then daily schedule adherence and Kanban system. Phan and Matsui (2010) suggested the more popular JIT elements for smoothing production flow, completing the daily schedule as time planned, and minimizing the variations in the daily workload are setup time reduction, and daily production schedule. This result contradicted with the findings of Salaheldin (2005) who revealed that in Egyptian companies, the least important element in JIT practices was to work overtime to complete daily schedules. Motwani (2003); Qureshi, Iftikhar, Bhatti, Shams and Zaman (2014); Al Haraisa (2017) found the most critical elements of JIT practices namely, setup time reduction, and 
using a Kanban system. Based on the above literature which argues that the common JIT practices are composed of three sub-constructs including setup time reduction, Kanban system and daily schedule adherence. The current study will depend on these three JIT practices.

\subsection{Research Framework}

\subsubsection{The relationship betwe- en MSD and setup time reduction}

MS is consistent objectives and action programs related to manufacturing function that aims to enhance the firm's capabilities as one of a firm's manufacturing strategy components which integrates with the firm's business strategy (Hallgren, 2007). Moreira et al. (2008) stated that based on an extensive review, implementing this strategic dimension help the employees to learn how reducing setup times. Yuan (2015) is consistent with the findings provided by (Prasad 1995) in preparing a formal planning of MS according with the targets of the corporate strategy and reducing setup times. Ditto, $\mathrm{Ph}$ an et al. (2006); Ward, McCreery and Anand (2007) and Abdallah et al. (2007) found significant and positive relationship between formal planning of MS and setup time reduction at the level of plant. Qureshi et al. (2014) found that minimizing setup time comes in the third rank that provides a continuous material flow between the plants in the manufacturing system. Sw-ink et al. (2005); Abdallah et al. (2007); Obamiro 2009; Rahmani, and Nayebi (2014) found positive relationship between the integration between business strategy and manufacturing strategy and setup time reduction. Al Haraisa (2017) proved the integration between the plant functions has a positive and significant impact on set up time reduction. Meanwhile, Dangayach et al. (2006) found negative relationship between the alignments of MS with business strategy to reduce setup times.Consequently, Gupta (2012) concluded that Gilgeous (2001) found significant relationship between adopting new technology and reducing setup times. Ortega Jimenez, Machuca, Garrido-Vega, and Díez Pérez (2009) found that adopting new technology will help the plant manager to focus on short setup times in order to avoid stopping the production lines. Dangayach et al. (2006) and Abdallah et al. (2007) found strong positive relationship between investing in several modern manufacturing technologies and setup time reduction. Cakmakci (2009); Gupta (2012); Kootanaee et al. (2013) supported the relationship between providing the workforce multiple skills and dealing with the new technology, the level of equipment utilization, and the frequency of machine breakdowns. This result is contradicted with the finding of Patil et al. (2016). Particularly in huge plants, educating managers is considered more important than educating the employees (Netland, 2016). Furthermore, manufacturing management should has enough ability to link between the commitment of implementing manufacturing strategic dimensions and the benefit derived from implementing JIT practices for improving the manufacturing performance (Singh et al. 2014). 
2.3.2The relationship between MSD and Kanban system

Results of Abdallah et al. (2007) found achievement of functional integration explain 14.2 percent of a total variance in JIT practices. Patil et al. (2012) found achievement of functional integration is in the second rank of JIT practices. Amoako-Gyampah et al. (2008) reported that MS became more interested toward continually learning, increasing knowledge, and developing skills for all employees and team work. Gupta (2012) and Phogat et al (2017) found significant influence of the integration between different functional areas in the organization on using Kanban system. Meanwhile, Van Wyk et al. (2016) found a shortage of empirical researches that examined the concept of achievement of functional integration from the perspective of manufacturing. Abdallah et al. (2007) showed positive and significant relationship between formal planning of MS and Kanban system. Fateh et al. (2012) stated that plant managers should focus on participating workers in problem solving, coordinating between all the functions based on using a Kanban container to control the production system and to avoid conflicts between them. Kumar and Panneerselvam (2006) found Kanban system contributes to help suppliers to deliver kanban containers to the plants without using separate packaging. However, GarridoVega et al. (2015) found no significant impact of formal planning of MS on adopting new technology. Fateha et al. (2012) proved that using Kanban system is required when writing the formal strategic planning processes. While, the study of Löfving et al. (2014) showed that till now there is no a proper framework of manufacturing strategy can be used in the empirical studies. Swink et al. (2005) and Abdallah et al. (2007) found positive relationship between the integration between business strategy, manufacturing strategy and Kanban system. Meanwhile, Dangayach et al. (2006) found negative relationship between them. Wang and Cao (2008) found a consistency among MS, business strategy, and the cooperation between other functional strategies with Kanban system. Obamiro (2009); Gupta (2012) and Garrido-Vega et al. (2015) found positive correlation between operations strategy and adopting Kanban system, but there is no significant impact of formal planning of MS on adopting new technology. However, Singh et al. (2012); Saukkonen et al. (2016) supported that plant managers should prepare the MS that allows to improve technical and managerial skills and to reconfigure the factory layout using Kanban system. Dangayach et al. (2006) found strong positive relationship between investing in manufacturing technologies and adopting Kanban system. These results is similar to the finding provided by Kumar et al. (2006) and Abdallah et al. (2007) which supported the relationship between factory automation using advance technology and using Kanban system in facilitating the flow of production system.

\subsubsection{The relationship betw- een MSD and daily sched- ule adherence}

Anticipating new manufacturing technology is required to facilitate the flow of product lines and to allow inserting the time of machines' breakdowns in 
the daily schedule (Furlan, Dal Pont, and Vinelli 2011; Zhao et al. 2011). Furthermore, manufacturing management should has enough ability to link between the commitment of implementing manufacturing strategic dimensions and the benefit derived from implementing JIT practices to adhere the plant schedule on a daily basis (Singh et al. 2014). Abdallah et al. (2007) showed positive and significant relationship between formal planning of MS and daily schedule adherence. This result is consistent with the finding of Patil et al. (2012). Qureshi et al. (2014) found that adherence of daily schedule provides a continuous material flow between the plants in the manufacturing system for utilizing time buffers to guard against unexpected stoppages in production. In addition, daily schedule adherence has the highest rank to impact on planned strategic performance, and equipment layout is in the second rank. Kumar et al. (2006) found that daily production schedule contributes to complete it as planned, and to insert extra time accommodating the breakdowns of machines. According to Matsui (2007), there is a significant difference between daily schedule adherence and the master schedule of production at the level of each industry. Phan et al. (2006) noted that formal manufacturing plan has a positive effect on completing the schedule of production and designing the layout of equipment. However, this result is contradicted with the findings of a study provided by (Salaheldin 2005) who found the lack of preparing formal strategic planning was the most common problem to implement JIT in Egyptian manufacturing companies. Swink et al. (2005) found positive relationship between the integration between business strategy and manufacturing strategy and daily schedule adherence. Meanwhile, Dangayach et al. (2006) found negative relationship between them. This result is not consistent with the finding of $\mathrm{Ab}$ dallah et al. (2007) and Garrido-Vega et al. (2015) who found that MS and business strategy have positive and significant impact on the adherence of daily production schedule to meet the production schedule each day, to build extra slack time into the daily schedule and to cover the unexpected production stoppages. Shavarini et al. (2013) and Rahmani et al. (2014) found the link between business strategy and functional strategies have positive and significant influence on the plant operational performance to complete the schedule on time. Brettel, Klein, and Friederichsen (2016) concluded that Swamidass and Newell (1987) supported the importance of using MS for achieving corporate goals and for meeting production schedule as planned. The findings of González-Benito and Suarez-González (2010) are consistent with the results of Nayebzadeh (2010) which proved the relationship between the role of manufacturing managers in assessing the alignment between MS and business strategy, and building reasonable daily production schedule. Finger et al. (2014) is consistent with the work provided by Porter (1985) who stated that most firms are needed to extensive technology to develop their manufacturing capabilities. In addition, the plant management should concern on continually training even for the highly skilled workers in order to match with the advanced manufacturing technology. Meanwhile, the finding of Ward et al. (2007) and Wang et 
al. (2008) revealed that previous literature were limited emphasis on assessing the relation between business strategies and manufacturing decisions about inve-sting in advanced technology for covering the production schedules. Abdallah et al. (2007) found that plant managers should focus on daily production schedule to avoid stopping the production lines. Besides, Dangayach et al.(2006) and Cakmakci (2009) found positive relationship between adopting different manufacturing technologies and both training and educating the employees to increase equipment utilization and to adhere daily production schedule. These results are similar to the finding provided by $\mathrm{Ku}-$ mar et al. (2006) which supported the relationship between using advance technology and scheduling multistage production system. This result of Ortega Jimenez et al. (2009) confirmed with the view of Sun and Hong (2002) who revealed that MS can link between business strategies and internal functions to maintain streamline of machines and to permit the organization to faster the response rate in order to meet customer needs. Patil et al. (2016) and Netland (2016) revealed that the plant management should have well defined formal strategy, and routinely reviewed it to support implementing daily production schedules in the multinational corporations, and considered Egypt was one of them.

\subsubsection{Framework and Resea- rch Hypotheses}

The framework of the current research was based on an empirical research which conducted by Abdallah et al. (2007). It was therefore important aim to identify the effects of the four dimensions of manufacturing strategy on JIT practices in some of Egyptian industrial companies. The framework of the current research depicted in figure 1 (see Appendix 2).

\subsubsection{Research Hypotheses}

Based on the aforementioned literature review and above discussion, the current research establishes the following hypotheses:

H1: There is a significant positive impact of manufacturing strategy dimensions on set-up time reductions.

H2: There is a significant positive impact of manufacturing strategy dimensions on using the of kanban system.

H3: There is a significant positive impact of manufacturing strategy dimensions on the adherence of the daily schedule.

\section{Methodology}

\subsection{Sample and Data Collec- tion}

Survey respondents at managerial positions had titles equivalent to manufacturing plant manager, assistant manager, or director of manufacturing plant, and dapartment managers include a wide range of functional areas (e.g., finance, accounting, marketing, production, human resources) are targeted to fill the questionnaire. Data was collected from 25 companies, and 233 managers have been participated in the study.The sampling frame included engineering and electronic, chemicals and food manufacturing companies in public sector. Out of the 41 respondents surveyed, 192 returned completed survey instruments for an overall response rate of $82.40 \%$. A stratified de- 
sign was used to randomly select an approximately equal number of firms in each three industrial sector. Therefore most of respondents are expected to be aware of JIT practices and have already implemented JIT techniques such as daily scheduling adherence, Kanban system, setup time reduction, cellular manufacturing as a subset of JIT practices (Salaheldin, 2005). Table 1 (see Appendix 2) presents the distribution of the sample according to industrial sector.

\subsection{Measures}

This research will explore the application of the four dimensions of MS, and three practices of JIT in some Egyptian industrial companies, and then examines the effect of these dimensions on JIT practices. This research consists of seven variables: four variables for the MSD (manufacturing strategy namely, achievement of functional integration, formal planning of manufacturing strategy, the link between manufacturing strategy and business strategy, and anticipating of new technology) and three of JIT practices (setup time reduction, Kanban system, and daily schedule adherence).

The questionnaire was developed after conducting an extensive review of relevant literature and included scales that were considered to have high content validity (e.g., Ahmad et al. 2002; Dangayach et al. 2004a, 2006b; Abdallah et al. 2007; Thun, 2008; Patil et al. 2012a, 2016b). The questionnaire (see appendix 1) contained two sections.The first consisted of 18 items that used to measure the construct of MSD as independent variable. Four items to measure achievement of functional integration, four items to meas- ure formal planning of manufacturing strategy, six items to measure the link between manufacturing strategy and business strategy and items items to measure anticipating of new technology. The respondents were asked to assess it using five-point Likert scale. The second consisted of 17 items to measure JIT practices as dependent variable. Six items used to measure setup time, 4 items to measure Kanban system, and seven items to measure daily schedule adherence. In the context of avoiding the current research of the differences related to the environment of the study sample in order to ensure clarity of meaning and equivalency, the original questionnaire was translated into Arabic language and was reverse translated into English again. Two academic researchers and two experts of operations management were asked to revise the translated questionnaire; and no changes were done to any of the questions. A pilot study is conducted to identify potential problem areas and deficiencies in the research instruments prior to implementation the full study. As well as to check whether respondents understand all the questions, whether any questions have a double meaning, and whether any useful ideas arise to develop the survey instrument (Hair, Money, Samouel, and Page 2007).

\subsection{Data Analysis}

Factor analysis was used to test the construct validity of the questionnaire to ensure that allitems that measure one variable are well correlated. According to Hair et al. (2007) rotation analysis is usually necessary to facilitate the interpretation of the extracted factors and suggested that factor load- 
ings greater than 0.50 should be considered to be significant.

Convergent was checked by factor analysis using the principal component analysis method with varimax rotation through Kaiser-Meyer-Olkin (KMO) test to predict if the questionnaire items were likely to be well factored or not (Nunnally 1978) and the overall value should be .60 or higher to proceed with factor analysis. Factors with eigenvalues greater than 1.0 were considered to determine the number of factors to be extracted (Hair et al. 2007).Cronbach's Alpha was used to test the inter-consistency of the questionnaire (Nunnally 1978). Multiple regressions was used to understand the causal relationship between one dependent variable and several independent variables (Hair et al. 2007) in order to test the second set of hypotheses by indicating the proportion of variance of each MSD process accounting for the JIT variances.

\section{Results}

\subsection{Convergent validity anal- yses}

The convergent validity was evaluated by examining the factor loadings of indicators. Using the criteria of an eigenvalue greater than one, the results indicated that there were four factors extracted to represent MSD items and one factor for JIT items. These factors accounted for $69.912 \%$ and $55.294 \%$, respectively, of the total variance and the KMO measure of sampling adequacy test accounted for $83.7 \%$ and $84.1 \%$, which were greater than the $60 \%$ as required by (Hair et al, 2007) which indicated above (see Tables 2, 3 and 4 in appendix 2).
These results considered to be satisfied for factor analysis as presented in table 5 and 6 in appendix 2 . The results showed that 17 item loadings on the four extracted factors were indicated (with loadings of more than .50) and one item was excluded (less than .50). The excluded item was: NT3. The results showed that 12 item loadings on the one extracted factor were indicated (with loadings of more than .50) and five items were excluded (less than .50). The excluded items were: STR3, STR5, DSA5, DSA6 and DSA7.

The items were aggregated by a factor analysis. Scales were tested for internal consistency reliability and construct validity as depicted in table 7 (see appendix 2). All coefficients of alpha range were between 0.751-0.809 which exceeded the standard of 0.70 according to Nunnally (1978), so the internal consistency of all constructs were considered to be sufficient.

\subsection{Descriptive Statistics}

Table 8 (see appendix 2) depicted a summary of descriptive statistics for the variables in the study. Mean standard deviations and Pearson correlation for the constructs. The results showed that all the variables have positive and significant relationships with the three indicators of JIT practices at $0.01 \mathrm{lev}$ el, with exception of the relationship between formal planning of manufacturing strategy and daily schedule adherence which is positive but not significant $(r=.08)$. From the foregoing, Pearson's coefficients reveled that there is a linear relationship between the four MSD and the three indicators of JIT practices. These results supported to accept hypothesis H1 and provid- 
ed more ground to perform multiple regression analysis.

\subsection{Regression Analysis}

The model depicted in Figure 1 was tested using regression analysis with SPSS 21 program. The research hypotheses were tested using regression analysis. Table 9, 10 and 11 show a summary of the hypotheses testing results. As for the effects of the four dimensions of MSD, the statistics in model 1 in table 9 (see appendix 2) signify that achievement of functional integration, formal planning of manufacturing strategy, the link between manufacturing and business strategy, and anticipating of new technology present positive impact on setup time reduction. By looking at the $\beta$ coefficients, achievement of functional integration tends to give higher impact $(\beta=0.48, \mathrm{t}=7.127)$, the link between manufacturing and business strategy $(\beta=0.43, t=5.157)$, formal planning of manufacturing strategy $(\beta=0.41, t=3.175)$, and anticipating of new technology $(\beta=0.32, \mathrm{t}=2.591)$. The explained variance of the overall model is $53 \%$. The previous evidence revealed the effect of these four MSD is verified. These results supported hypothesis $\mathrm{H} 1$.

Table 10 (see appendix 2) exhibits that $31 \%$ of the variance in the Kanban system as a dependent variable is explained by model 2 . The results show that only three out of four MSD, achievement of functional integration, the link between manufacturing and business strategy, and anticipating of new technology have significant and positive impact on Kanban system. By observing the Beta coefficient, the effect of linking between manufacturing and business strategy exhibits to be higher impact $(\beta=0.35, \mathrm{t}=4.599)$, then the effect of anticipating of new technology $(\beta=0.33, t=3.794)$, and the effect of achievement of functional integration is relatively weak $(\beta=0.28$, $\mathrm{t}=4.203$ ). While the effect of formal planning of manufacturing strategy fails to significantly explain the impact on Kanban system $(\beta=0.18, \quad \mathrm{t}=1.022)$. Hence, the effect of formal planning of manufacturing strategy is not revealed. These results supported partially hypothesis $\mathrm{H} 2$.

As shown in table 11 (see appendix 2), $\mathrm{R}^{2} 0.44$ indicates that $44 \%$ of the variance in the daily schedule adherenceisexplained by model $3(\mathrm{~F}=27.468$ $, \mathrm{P}<.01)$. The results show that both of the achievement of functional integration $(\beta=0.44, \mathrm{t}=7.382)$, and anticipating of new technology $(\beta=0.42, \mathrm{t}=$ $6.135)$ have positive and significant impact on daily schedule adherence. These finding proved that these two dimensions seem to be only responsible for predicting daily schedule adherence. Whilst, the impact of both of the linking between manufacturing and business strategy $(\beta=0.19, \quad \mathrm{t}=1.193)$ and formal planning of manufacturing strategy $(\beta=0.12, \mathrm{t}=1.051)$ exhibited positive but not significant effect on daily schedule adherence. These results supported partially hypothesis H3.

\section{Discussion and Conclusi- ons}

The results of testing the hypotheses suggest the acceptance of $\mathrm{H} 1$ and partially acceptance of $\mathrm{H} 2$ and $\mathrm{H} 3$ regarding to the proposed influence of four MS dimensions on three indicators of JIT practices. The results of this study confirmed the importance of achievement of functional integration to 
reduce the setup time in the sample of Egyptian companies. Based on this result, the plant managers aware of the importance of the integration of the plant functions and have abilities to solve the problems to reduce the setup times. In particular, these results confirmed with similar findings from prior research such as Abdallah et al (2007); Patil (2012); and Al Haraisa (2017).

The findings highlighted the high relatively influence of formal planning of MS on setup time reduction. This indicates that plants' managers can better understand the factors that may have significant influence on reducing setup time in Egyptian companies. This result is consistent with the work of Phan et al (2006); Ward et al (2007); Abdallahet al(2007); Cakmakci (2009) ; Qureshi et al (2014) which suggested that formal planning of MS and the link between manufacturing and business strategy have strong positive and significant impact on setup time reduction. However, this result is not consistent with the work of Dangayach et al (2006); Patil et al (2012a, 2016b) which found negative impact of linking between manufacturing and business strategy on setup time reduction. The positive empirical results justify that the theoretical bases of anticipating of new technology dimension provides positive impact on setup time reduction. This finding is more consistent with the work of Gupta (2012). The finding of current research is consistent with many previous researches (Diaz et al. 2010; Singh et al. 2012a, 2014; Van Wyk et al. 2016; Phogat et al. 2017) which revealed that achievement of functional integration is an important factor to implement Kanban system. This result indicates that by coordinating the work system between the functions, any problems done with their suppliers regarding the orders can be solved easily. As regards formal planning of MS, the results found positive but not significant impact on Kanban system. This finding is not totally surprising given that support the observations of Salaheldin (2005) who found that this dimension is the most important problem which is not well defined in Egyptian companies. This result also reflects that the Egyptian companies have a lack of formal planning of MS, or may be their plant managers needed to continuously review and update their strategic plans, or may be their suppliers used separate packaging in order to fill and deliver their orders rather than using Kanban containers. The results showed that the link between manufacturing and business strategy is the highest relatively influence on implementing Kanban system in the Egyptian companies. This result is confirmed with the results of empirical studies provided by the work of Abdallah et al (2007); Obamiro (2009); Rahmani et al (2014). Furthermore, this finding supports argument provided by Kumar et al (2006) ; Abdallah et al (2007); Furlan et al (2011); Saukkonen et al (2016) which found a relationship between pursuing the plant's manager for implementing the new manufacturing practices depending on long-range programs of technology, and controlling the manufacturing plans by using a Kanban system.

In addition to previous studies (Fateh et al. 2012; Finger et al. 2014; Phogat et al. 2017), this research provides another piece of evidence that achievement of functional integration 
is one of the most important dimension that have strong impact on daily schedule adherence. This result indicated that the plant's managers are keen on the importance of meeting the daily production schedule as planned. However, the present research failed to $\mathrm{pr}$ ove significant impact of a formal planning of MS on daily schedule adherence which is consistent with the previous work of Ortega Jimenez et al (2009). This result indicated that the plant managers in the sample of Egyptian companies should assess their strategic plans and define well the targets of their strategic planning process that enable them to build reasonable production schedules for completing them on time. Meanwhile, this result is contradicted with some studies (Abdallah et al. 2007; Cakmakci 2009; Qureshi et al. 2014; Khaireddin et al. 2015). As for the effects of linking between manufacturing and business strategy, the present research failed to prove significant impact on daily schedule adherence which is similar with the finding of Patil et al (2012). It is not surprisingly to find this result, may be because of the barriers in Egyptian companies with suppliers which impact on having reasonable daily schedules. For instance, potential investments needed for restructuring manufacturing companies, limited financial resources, and lack of information required to translate business strategy into manufacturing terms. However, this result is contradicted with the theoretical basis that built on the previous work of Dangayach et al (2006); Abdallah et al (2007); Garrido-Vega et al (2015); Brettel et al (2016). The current research provides evidence on the impact of anticipating of new technology on dai- ly schedule adherence. This finding is consistent with Kumar et al (2006); Cakmakci (2009); Saukkonen et al (2016) who focused on the importance of this dimension to support the manufacturing capabilities that required to complete the production schedules on time. Nevertheless, this finding is contradicted with the work of Ward et al (2007) who stated this dimension is not a key factor to impact on the effectiveness of production schedules.

The motivation of this study was the lack of empirical evidence regarding the influence of MS dimensions on JIT practices. Using a more recent data set of Egyptian industrial companies, the results of this research validate the importance of MS dimensions in explaining JIT practices. The model that has been presented in this research has a theoretical basis and highlights the key components of MS and JIT practices reported by Abdallah et al (2007). While, through the empirical validation its results provide contribution to the growing empirical base of literature in the operations management area, and several useful points are revealed. It also helps plant managers to adopt proper dimensions of MS with regard to achievement of functional integration, formal planning of MS, the link between manufacturing and business strategy, and anticipating of new technology for implementing JIT practices.

The results of regression analysis accounted for less total variance in Kanban system than in daily schedule adherence and setup time reduction (.31 as opposed to .44 , and .53 respectively), although the same four MS dimensions seem to be responsible for 
predicting the practices of setup time reduction, Kanban system, and daily schedule adherence.The findings suggested that achievement of functional integration, the link between manufacturing and business strategy, and formal planning of MS showing higher impact than anticipating of new technology on implementing setup time reduction.The results highlighted the importance of linking between manufacturing and business strategy, anticipating of new technology, and achievement of functional integration to be an important infrastructure for implementing the practices of Kanban system. The results revealed that policy makers at the level of each plant should review its missions, modify their long-range visions to consider formal planning of MS as a key determinant to adopt Kanban system. The findings also pointed out that, achievement of functional integration, and anticipating of new technology can contribute to the plant capability in implementing daily production schedule practices (Fateha et al. 2012). The link between MS and business strategy does not contribute to impact on preparing and adhering proper production schedules. Top management in Egyptian companies requires removing the barriers as a result of the weakness of managerial practices that prevent coordinating between MS and business strategy. Egyptian plant managers needed to be involved in preparing the manufacturing strategy, to insert their requirements into the business strategy considering it as a part of corporate strategy and to achieve better understanding the key elements of translating their business strategy into manufacturing terms.

\section{Limitations and Future Re-} search

Reexamining the hypothesized relationships in this study will contribute to the building of a consistent body of knowledge, particularly if researchers investigate other MS dimensions including communication of manufacturing strategy (Abdallah et al., 2007); manufacturing as a competitive force (Patil et al., 2012) to investigate their possible impact on JIT practices between the industries in Egyptian environment and in other different environments. Researchers in Arabian countries need to give more attention to validate research instruments used in this reseach (e.g., Salaheldin 2005, conducted in Egypt; Khaireddin et al. 2015, conducted in Jordan). The replication of this research is needed to execute more research in this field and to identify other than variables investigated can explain more variance in explaining JIT practices .

Future research should investigate other types of indicators to measure JIT practices such as JIT delivery by suppliers, JIT link with customers, the use of MRP at the time of production, information system and equipment layout (Abdallah et al. 2007; Phan et al. 2010, Rahmani et al. 2014) because these may be have more direct affect the dimensions of manufacturing strategy.

In addition, the possibility to generalize the findings of this research in other Egyptian industrial sector can be made cautiously. Because data collected to analyze this research was only in companies from three public industrial sectors. Replication of this research can enable the researchers collect data 
from other sectors to attempt comparison between the public and private Egyptian companies. This can generate new findings to enhance widely understanding the relationships between the MS dimensions and JIT practices.

\section{References}

1. Abdallah, A. B., and Matsui, Y. (2007), "The Relationship between JIT Production and Manufacturing Strategy and Their Impact on JIT Performance", Paper Presented at POMS (Production and Operations Management Science) $18^{\text {th }}$ annual conference, Dallas, Texas, U.S.A, May 4 to May 7.

2. Aboutalebi, R. (2016), "International Manufacturing Strategies: A Taxonomy", In: BAM (British Academy of Management), Proceeding, $30^{\text {th }}$ Annual Conference of BAM: Thriving in Turbulent Time, Newcastle University, England, UK, September 6-8.

3. Ahmad, A., Mehra., and Pletcher, M. (2002), "The Declining Need for Traditional Performance Measures In JIT Practices", Journal of Business Administration, Vol.1, No .2 , Fall.

4. Ahmad, S., Schroeder, R. G., and Sinha, K. K. (2003), "The Role of Infrastructure Practices in the Effectiveness of JIT Practices: Implications for Plant Competitiveness", Journal of Engineering and Technology Management, Vol. 20, Issue. 3, September, pp: 161-191.

Doi. org/10.1016/S0923-4748 (03) 00017-1

5. Al Haraisa, Z. E. (2017), "Just-InTime System and Its Impact on Operational Excellence: An Empirical Study on Jordanian Industrial Com- panies", International Journal of Business and Management, Vol. 12, No. 12, August, pp: 158-167. Doi. org/10.5539/ijbm.v12n12p158

6. Amoako-Gyampah, K., and Acquaah, M. (2008), "Manufacturing Strategy, Competitive Strategy and Firm Performance: An Empirical Study in a Developing Economy Environment", International Journal of Production Economics, Vol. 11l, No. 2, pp: 575-592. Doi:10.1016/j.ijpe.2007.02.030

7. Brettel, M., Klein, M., and Friederichsen, N. (2016), "The Relevance of Manufacturing Flexibility in the Context of Industrie 4.0", 48th CI$R P$ Conference on Manufacturing Systems-Procedia CIRP CMS 41, pp: 105-110. Doi. 10.1016/j.procir. $\underline{2015.12 .047}$

8. Cakmakci, M. (2009), "Process Improvement: Performance Analysis of the Setup Time Reduction-SMED in the Automobile Industry", International Journal of Advanced Manufacturing Technology, Vol. 41, pp: 168-179. Doi. 10.1007/ s00170-008-1434-4

9. Chen, Z., and Tan, K. H. (2013), "The Impact of Organization Ownership Structure on JIT Implementation and Production Operations Performance", International Journal of Operations \&Production $M$ anagement, Vol. 33, No. 9, pp: 1202-1229. Doi.10.1108/IJOPM-062011-0207

10.Cua, K.O., McKone, K.E., Schroeder, R.G. (2001), "Relationships between Implementation of TQM, JIT, and TPM and Manufacturing Performance," Journal of Operati- 
ons Management, Vol. 19, pp: 675694.

11.Dangayach, G. S., and Deshmukh, S. G. (2004), "Linkages between Manufacturing Strategy, Business Strategy and Business Excellence: A Longitudinal Study", International Journal of Industrial Engineering, Vol. 11, No. 3, pp: 297-306.

12.Dangayach, G. S., and Deshmukh, S. G. (2006), "An Exploratory Study of Manufacturing Strategy Practices of Machinery Manufacturing Companies in India", Omega, Vol. 34, No. 3, pp: $254-273$.

13.Diaz, R., and Ardalan, A. (2010), "An Analysis of Dual-Kanban Justin-Time Systems in a Non-Repetitive Environment", Production and Operations Management Society, Vol.19, No. 2, March-April, pp: 233-245. Doi. 10.3401/ poms. 1080.01075

14.Dombrowski, U., Intra, C.,Zahn, T., and Krenkel, P. (2016), "Manufacturing Strategy-a Neglected Success Factors for Improving Competitiveness", Proceeding, $48^{\text {th }}$ CIRP Conference on Manufacturing Systems, Procedia CIRP, Vol. 41, 9-14. Doi.10.1016/j.procir.2015.12.118

15.Fateha, A. A. N, Nafrizuan, M. Y., and Razlan, Y. A. (2012), "Review on Elements of JIT Implementation", International Conference on Automotive, Mechanical and Materials Engineering (ICAMME'2012), Penang (Malaysia), May 19-20.

16.Finger, A. B., Flynn, B. B., and Paiva, E. L (2014), “Anticipation of New Technologies:Supply Chain Antecedents and Competitive Performance", International Journal of Operations \& Production Man- agement, Vol. 34, No. 6, pp: 807828. Doi.10.1108/IJOPM-09-2012$\underline{0386}$

17.Flynn, B., Sakakibara, S., and Schroeder, R. G. (1995), "Relationship between JIT and TQM: Practices and Performance", Academy of management Journal, Vol. 38, No. 5, pp: 1325-1360.

18.Flynn, B. B., Schroeder, R. G., Flynn, E. J., Sakakibara, S., and Bates, K. A.(1997), "World-Class Manufacturing Project: Overview and Selected Results," International Journal of Operations \& Production Management, Vol. 17, No.7, pp: 671-685. Doi. Org /10. 1108/01443 $\underline{579710175592}$

19.Fullerton, R. R., and McWatters, C. S. (2001), "The Production Performance Benefits From JIT Implementation", Journal of Operations Management, Vol. 19, Issue. 1, January, pp: 81-96. Doi.org /10. 1016 /S0272-6963(00)00051-6

20.Furlan, A., Dal Pont, G., and Vinelli, A. (2011), "On the Complementarity Between Internal and External Just-in-Time Bundles to Build and Sustain High Performance Manufacturing", International Journal of Production Economics, Vol. 133, No. 2, pp: 489-495. Doi. org/10. 1016/j.ijpe.2010.07.043

21.González-Benito, J., and SuarezGonzález, I. (2010), “A Study of the Role Played by Manufacturing Strategic Objectives and Capabilities in Understanding the Relationship between Porter's Generic Strategies and Business Performance", British Journal of Management, Vol. 21, No. 4, pp: 1027- 
1043. Doi. 10.1111/j.1467-8551. 2008.00626.x

22.Grant, N. (2013), “A Taxonomy of Manufacturing Strategies in Manufacturing Companies in Ireland", Journal of Manufacturing Technology Management, Vol. 24, Issue. 4, pp: 488-510. Doi. 10. 1108/17410 $\underline{381311327378}$

23.Gupta, A. K. (2012), “Just in Time Revisited: Literature Review and Agenda for Future Research", International Journal of Research in Mechanical Engineering \& Technology, Vol. 2, Issue. 1, April, pp: 969-971.

24.Hair, J. F., Money, A. H., Samouel, P., and Page, M. (2007), "Research Methods for Business", John Wiley and Sons Ltd.

25.Hallgren, M. (2007), "Manufacturing Strategy, Capabilities and Performance", Doctoral Dissertation in Production Economics, University of Linköping, PhD thesis.

26. Hallgren, M., and Olhager, J. (2006), "Quantification in Manufacturing Strategy: A Methodology and Illustration", International Journal of Production Economics, Vol. 104, February, pp: 113-124. Doi.10.10 16/j.ijpe.2005.09.004

27.Hashim, M. M. K. I (2010), "Implementation of Project Management, Erp, Jit, Scm, Tqm and Tpm: Empirical Study of Egyptian and Chinese Manufacturing Firms", City International University, Press Services, USA.

28.Jia, G. Z., and Bai, M. (2011), “An Approach for Manufacturing Strategy Development Based on FuzzyQFD”, Journal of Computers \& In- dustrial Engineering, Vol. 60, pp: 445-454. Doi. 10.1016/j.cie.2010. $\underline{07.003}$

29. Ortega Jimenez, C H., Machuca, J. A. D., Garrido-Vega, P., and Díez Pérez, J. L. (2009), "Manufacturing Strategy and Technology Interaction: Fit Line \& Impact", Paper presented at the meeting of POMS $20^{\text {th }}$ Annual Conference, Orlando, Florida U.S.A, May 1-4.

30.Garrido-Vega, P., Ortega Jimenez, C. H., Díez Pérez, J. L., and Morita, M. (2015), "Implementation of Technology and Production Strategy Practices: Relationship Levels in Different Industries", International Journal of Production Economics, Vol. 161, March, pp: 201-216. Doi.org/10.1016/j.ijpe.2014.07.011

31. Khaireddin, M., and Abu Assab, M. I. E., Nawafleh, S. A. (2015), "Justin-Time Manufacturing Practices and Strategic Performance: An Empirical Study Applied on Jordanian Pharmaceutical Industries", International Journal of Statistics and Systems, Vol. 10, No. 2, pp: 287307

32.Kootanaee, A. J., Babu, K. N., and Talari, H. F. (2013), "Just-in-Time Manufacturing System: From Introduction to Implement", International Journal of Economics, Business and Finance, Vol. 1, No. 2, March, pp: 07-25.

33.Kumar, C. S., and Panneerselvam, R. (2006), "Literature Review of JIT-Kanban System", The International Journal of Advanced Manufacturing Technology", Vol. 32, Issue. 3-4, March, pp: 393-408. Doi. 10.1007/s00170-005-0340-2 
34.Löfving, M., Säfsten, K. and Winroth, M. (2014), "Manufacturing Strategy Frameworks Suitable for SMEs", Journal of Manufacturing Technology Management, Vol. 25, No. 1, pp: 7-26. Doi. 10.1108/ JMTM-08-2012-0081

35.Mackelprang, A. W., and Nair, A. (2010), "Relationship between Justin-Time Manufacturing Practices and Performance: A Meta-Analytic Investigation", Journal of Operations Management, Vol. 28, Issue. 4, July, pp: 283-302. Doi.10.1016/ j.jom.2009.10.002

36.Matsui, Y. (2002), “Contribution of Manufacturing Departments to Technology Development: An Empirical Analysis for Machinery, Electrical and Electronics, and Automobile Plants in Japan", International Journal of Production Economics, Vol. 80, Issue. 2, November, pp: 185-197. Doi. org/10.1016 /S0925-5273(02)00317-1

37.Matsui, Y. (2007), “An Empirical Analysis of Just-in-Time Production in Japanese Manufacturing Companies", International Journal of Production Economics, Vol. 108, Issue 1-2, July, pp: 153-164. Doi. 10.1016/j.ijpe.2006.12.035

38.McGrath, M. E., and Hoole, R.W. (1992), "Manufacturing's New Economies of Scale", Harvard Business Review, Vol. 70, No. 3, pp: 94-102.

39.Moreira, M. R., and Alves, R. A. (2008), "A Study on Just-in-Time Implementation in Portugal: Some Empirical Evidence", Brazilian Journal of Operations \& Production Management, Vol. 5, No. 1, pp: 0522.
40.Nayebzadeh, S. (2010), "The Relationship between Alignment of $\mathrm{Bu}$ siness Strategy-Manufacturing Strategy and Performance", International conference On Management Practices for Sustainable Growth (ICMPSG), Tamil Nadu, India, July 28-30.

41.Netland, T. H. (2016), "Critical Success Factors for Implementing Lean Production:The Effect of Contingencies", International Journal of Production Research, Vol. 54, No. 8, pp: 2433-2448. Doi.org/10. 1080/00207543.2015.1096976

42. Obamiro, J. K. (2009), "Exploring the Relationships between Just-InTime Technique and Manufacturing Performance: Empirical Evidence From Selected Nigerian Firms", Manager Journal, Vol. 10, pp: 165176.

43. Ocampo, L. A., and Clark, E. E. (2015), "A Sustainable Manufacturing Strategy Framework: The Convergence of Two Fields", Asian Academy of Management Journal, Vol. 20, No. 2, pp: 29-57.

44.Patil, P.P., Narkhede, B.E. and Akarte, M.M. (2012), “An Exploratory Study of Manufacturing Strategy of Packaging Product Manufacturing Companies in India", International Journal of Quality Rese-arch, Vol. 6, No. 3, pp: 233-249.

45.Patil, P.P., Narkhede, B.E. and Akarte, M.M. (2016), "Manufacturing Strategy Implementation and Performance Benchmarking in Indian Packaging Product Manufacturing Companies", International Journal of Competitiveness, Vol. 1, No. 1, pp: 33-52, January. Doi.10.1504/IJC.2016.075888 
46.Phan, C. A., and Matsui, Y. (2006) "Empirical Study on Effect of JIT Practices on Competitive Performance in Japanese Manufacturing Companies" Proceeding, 17th Annual Conference of Production and Operation Management Society ( $P$ OMS), Boston, United States (April 28-May 1).

47.Phan, C. A., and Matsui, Y. (2010), "Contribution of Quality Management and Just-in-Time Production Practices to Manufacturing Performance", International Journal of Productivity and Quality Management, Vol. 6, Issue 1, pp: 23-47, January. Doi. 10.1504/IJPQM.2010. 033883

48.Phogat, S., and Gupta, A. K. (2017) , "Theoretical Analysis of JIT Elements for Implementation in Maintenance Sector", Uncertain Supply Chain Management Journal, Vol. 5, Issue. 3, pp: 187-200. Doi. 10.5267/j.uscm.2017.1.003

49.Prasad, B.(1995), “JIT Quality Matrices for Strategic Planning and Implementation", International Journal of Operations \& Production Management, Vol. 15, Issue. 9, pp: 116-142. Doi. org/10.1108/014435 79510099706

50.Qureshi, M. I., Iftikhar, M., Bhatti, M. N., Shams, T., and Zaman, K. (2014), "Critical Elements in Implementations of Just-in-Time Management: Empirical Study of Cement Industry in Pakistan, SpringerPlus, Vol. 2, No. 1, pp: 1-14. Doi: 10.1186/2193-1801-2-645

51.Rahmani, K., and Nayebi, M. A. (2014), "Effect of JIT Implementation in Iran Automotive Industry (Case Study: Iran Khodro's Assem- bly Line 2)", Indian Journal of Scientific Research, Vol. 7, No. 1, pp: 001-016.

52.Sakakibara, S., Flynn, B. B., and Schroeder, R. G. (1993), "A Framework and Measurement Instrument for Just-In-Time Manufacturing," Journal of Production \& Operations Management, Vol. 2, Issue.3, pp: 177-194, September.

53.Doi.10.1111/j.1937-5956.1993.tb 00097.x

54.Sakakibara, S., Flynn, B. B., Schroeder, R.G. and Morris, W. T. (1997), The Impact of Just-in-Time Manufacturing and Its Infrastructure on Manufacturing Performance, Management Science, Vol. 43, Issue. 9, pp: 1246-1257, September. Doi.org/10.1287/mnsc.43.9.1246

55.Salaheldin, S. I. (2005), "JIT Implementation in Egyptian Manufacturing Firms: Some Empirical Evidence", International Journal of Operations \& Production Management, Vol. 25, Issue. 4, pp: 354370.

Doi.10.1108/01443570510585543

56.Saukkonen, J., Vasamo A-L., Ballard, S., and Levie, J. (2016), “Anticipation of Technology as an Entrepreneurial Skill", Proceedings of the $11^{\text {th }}$ European Conference on Innovation and Entrepreneurship, pp: 717-725, September 15-16.

57.Shah, R., and Ward, P. T. (2003), "Lean Manufacturing: Context, Practice Bundles, and Performance", Journal of Operations Management, Vol. 21, Issue. 2, pp: 129-149. Doi.org/10.1016/S0272-6963 (02)00108-0

58. Shavarini, S. K., Salimian, H., Nazemi, J., and Alborzi, M. (2013), 
"Operations Strategy and Business Strategy Alignment Model (Case of Iranian Industries)", International Journal of Operations \& Production Management, Vol. 33, Issue. 9, pp: 1108-1130. Doi.org/10.1108/IJ OPM-12-2011-0467

59.Singh, G and Ahuja, I. S. (2012), "Just-in-Time Manufacturing: Literature Review and Directions", International Journal of Business Continuity and Risk Management, Vol. 3, No. 1, pp: 57-98. Doi.10. 1504/IJBCRM.2012.045519

60.Singh, G and Ahuja, I. S. (2014), "An Evaluation of Just In Time (JIT) Implementation on Manufacturing Performance in Indian Industry", Journal Of Asia Business Studies, Vol. 8, Issue. 3, pp: 278-294. Doi.org/10.1108/JABS-09-20130051

61.Swink, M., Narasimhan, R., and Kim, S. W. (2005), "Manufacturing Practices and Strategy Integration: Effects on Cost Efficiency, Flexibility, and Market-Based Performance", Journal of the Decision Sciences Institute, Vol. 36, Issue. 3, pp: 427-457, August.

62.Doi.10. 1111/j. 1540-5414. 2005. 00079. x

63.Thun, J-H (2008), "Empirical Analysis of Manufacturing Strategy Implementation", International Journal Production Economics, Vol. 113, Issue.1, pp: 370-382. Doi.10. 1016/j.ijpe.2007.09.005

64. Wang, J., and Cao, D-B. (2008), "Relationships Between two Approaches for Planning Manufacturing Strategy: A Strategic Approach and A Paradigmatic Approach", International Journalof
Production Economics, Vol. 115, Issue. 2, pp: 349-361, October. Doi.org/10.1016/j.ijpe.2008.04.0 14

65. Wang, J., Chen, Z-x., and Wang, P-p. (2016), “An Empirical Study on Manufacturing Strategy Formulation in Turbulent Environment: Dealing with Changes and Uncertainties", Proceedings of the $23^{\text {rd }}$ International Conference on Industrial Engineering and Engineering Management. Doi.10.2991/978-94-6239-2557_14

66.Ward, P. T., McCreery, J. K., and Anand, G. (2007), "Business Strategies and Manufacturing Decisions: An Empirical Examination of Linkages", International Journal of $O p$ erations \& Production Management, Vol. 27, Issue. 9, pp: 951973.

Doi.org/10.1108/0144357071077 5810

67. Van Wyk, G., and Naidoo, V. (2016), "Critical Assessment of Just-in-Time (JIT) Process within a South African Company: The Case of Sabertek", Investment Management and Financial Innovations Journal, Vol. 13, Issue. 3, pp: 237247. Doi.org/10.21511/imfi.13(31).2016.10

68. Yuan, B. Z. (2015), "Impact of JIT Practices and Lean Practices on Operational Performance in Malaysia Packaging Industry: Internal Integration as a Mediator", Master Dissertation in Business Administration, Universiti Sains Malaysia, Master thesis. 


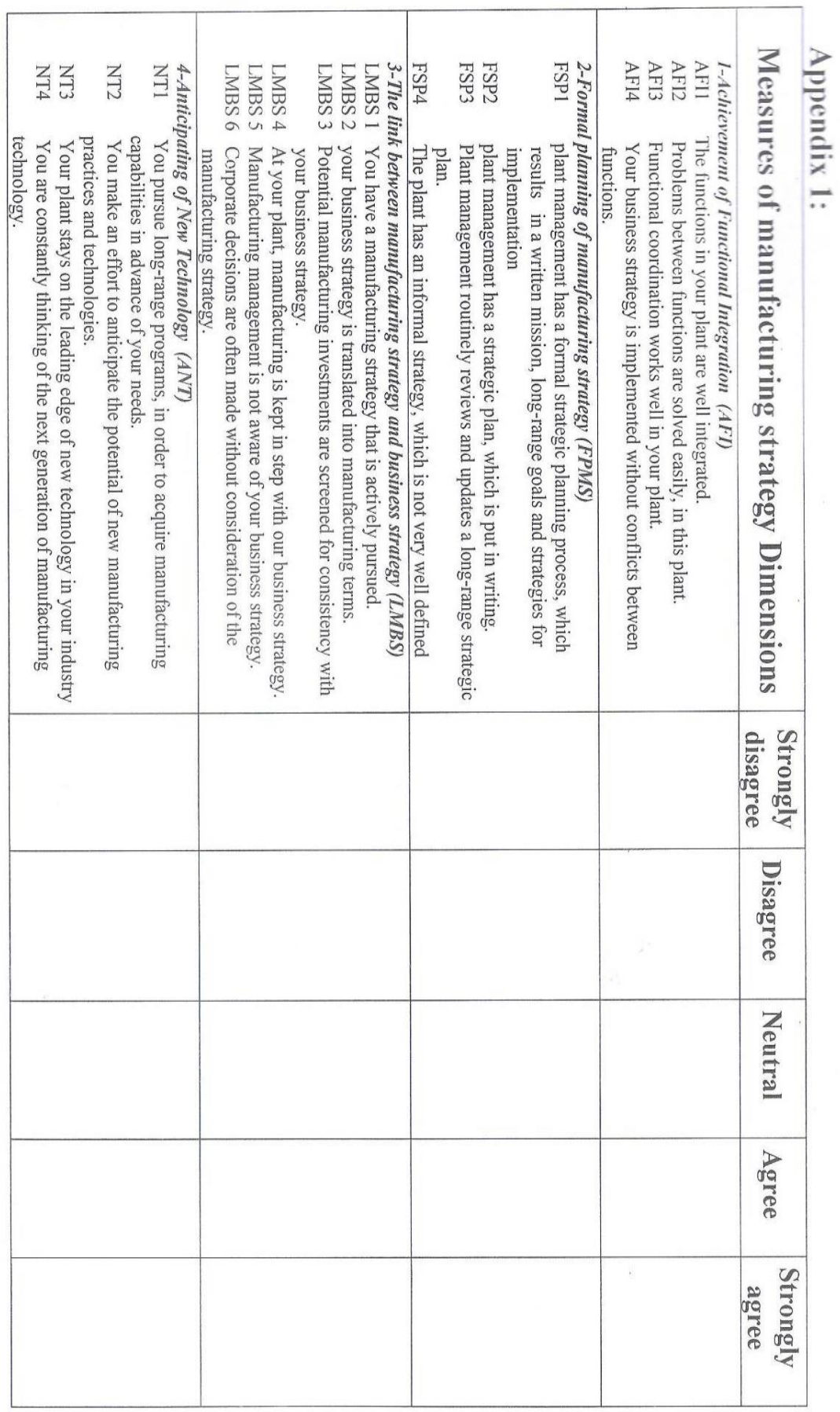




\begin{tabular}{|c|c|c|c|}
\hline \multirow[t]{6}{*}{ 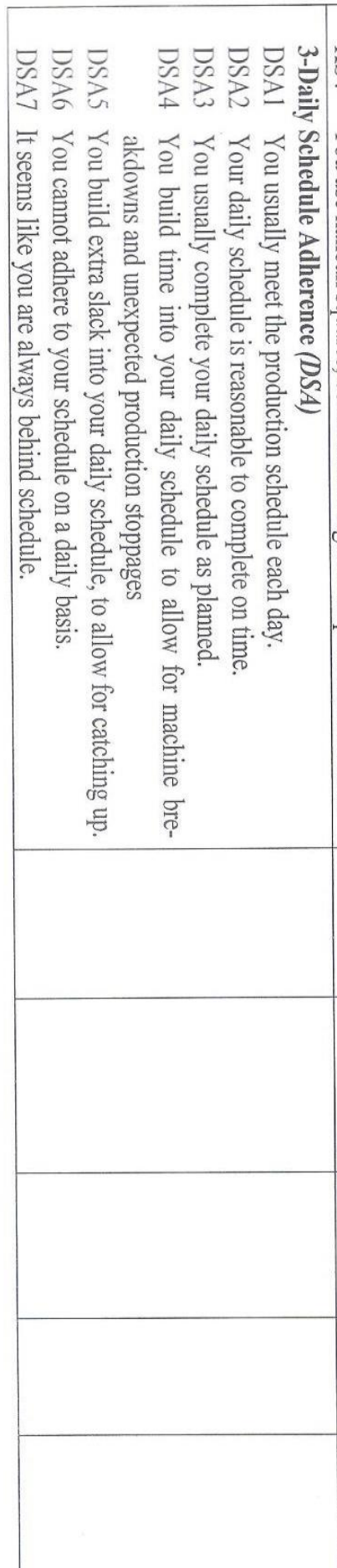 } & 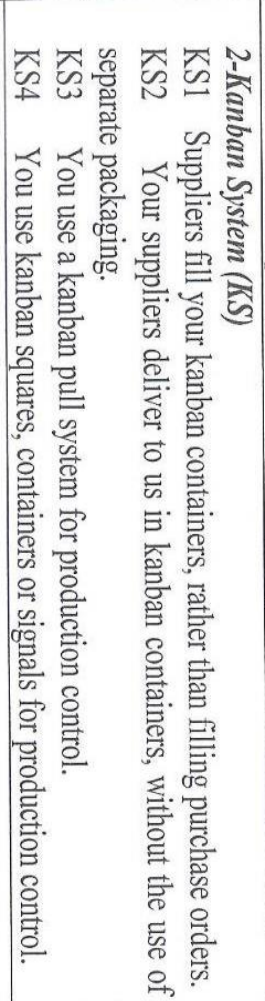 & 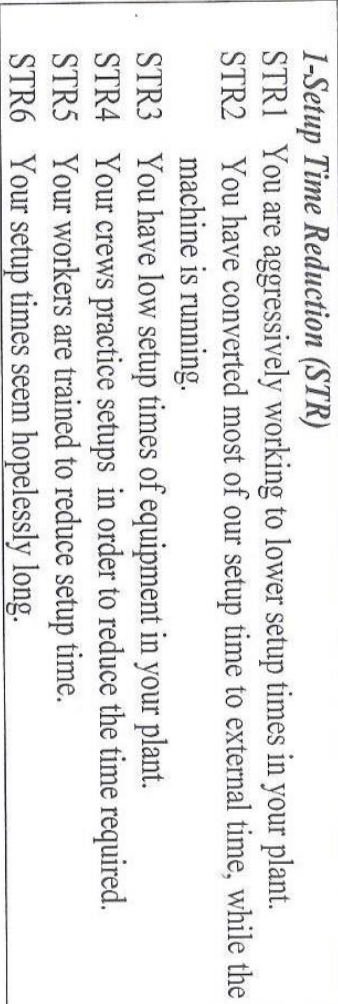 & 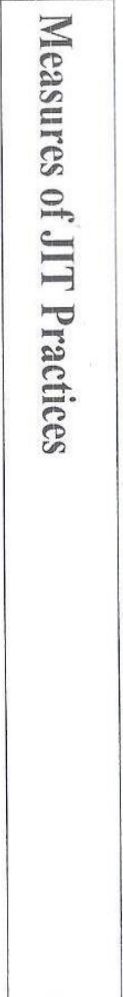 \\
\hline & & & 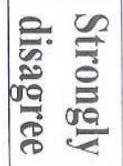 \\
\hline & & & 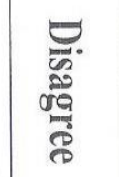 \\
\hline & & & 胥 \\
\hline & & . & 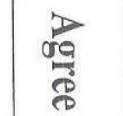 \\
\hline & & & 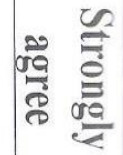 \\
\hline
\end{tabular}




\section{Appendix 2:}

\section{Table 1: Description of the sampled companies according to industry type}

\begin{tabular}{|l|c|c|}
\hline Manufacturing sector & No. of firms & Percent \\
\hline Engineering and Electronics & 8 & $32 \%$ \\
\hline Chemicals & 9 & $36 \%$ \\
\hline Food & 8 & $32 \%$ \\
\hline Total & 25 & 100 \\
\hline
\end{tabular}

Table 2: Total variance explained

\begin{tabular}{|c|c|c|c|c|c|c|c|c|c|}
\hline \multirow{2}{*}{ Component } & \multicolumn{3}{|c|}{ Initial Eigenr alues (MSD) } & \multicolumn{3}{|c|}{ Extraction Sums of Squared Loadings } & \multicolumn{3}{|c|}{ Rotation Sums of Squared Loadings } \\
\hline & Total & $\%$ of Variance & Cumulative $\%$ & Total & $\%$ of Variance & Cumulative \% & Total & $\%$ of Variance & Cumulative $\%$ \\
\hline 1 & 7.538 & 41.879 & 41.879 & 7.538 & 41.879 & 41.879 & 4.190 & 23.281 & 23.281 \\
\hline 2 & 2.400 & 13.332 & 55.211 & 2.400 & 13.332 & 55.211 & 3.299 & 18.325 & 41.606 \\
\hline 3 & 1.471 & 8.172 & 63.384 & 1.471 & 8.172 & 63.384 & 2.776 & 15.422 & 57.028 \\
\hline 4 & 1.175 & 6.528 & 69.912 & 1.175 & 6.528 & 69.912 & 2.319 & 12.884 & 69.912 \\
\hline
\end{tabular}

Extraction Nethod: Principal Component Analysis.

MDD: Manufacturing strategy Dimensions

Table 3: variance explained Total Variance Explained

\begin{tabular}{|c|c|c|c|c|c|c|}
\hline \multicolumn{5}{|c|}{ Total Variance Explained } \\
\hline \multirow{3}{*}{ Component } & \multicolumn{2}{|c|}{ Initial Eigenvalues (JIT) } & \multicolumn{3}{|c|}{$\begin{array}{c}\text { Extraction Sums of Squared } \\
\text { Loadings }\end{array}$} \\
\cline { 2 - 7 } & Total & $\begin{array}{c}\text { \% of } \\
\text { Variance }\end{array}$ & $\begin{array}{c}\text { Cumulative } \\
\%\end{array}$ & Total & $\begin{array}{c}\text { \% of } \\
\text { Variance }\end{array}$ & Cumulative \% \\
\hline $\mathbf{1}$ & 2.212 & 55.294 & 55.294 & 2.212 & 55.294 & 55.294 \\
\hline
\end{tabular}

Extraction Method: Principal Component Analysis.

JIT: Just in Time 
Table 4: KMO and Bartlett's Test

\begin{tabular}{|l|c|c|c|}
\hline \multicolumn{3}{|c|}{ MSD } & JIT \\
\hline Kaiser-Meyer-Olkin Measure of Sampling Adequacy & $\mathbf{. 8 3 7}$ & $\mathbf{. 8 4 1}$ \\
\hline \multirow{3}{*}{ Bartlett's Test of Sphericity } & Approx. Chi-Square & $\mathbf{1 6 0 8 . 8 5 6}$ & $\mathbf{1 1 6 9 . 5 9 2}$ \\
\cline { 2 - 4 } & $\mathrm{df}$ & 153 & 91 \\
\cline { 2 - 4 } & Sig. & .000 & .000 \\
\hline
\end{tabular}

KMO: Kaiser-Meyer-Olkin

\section{Table 5: Rotated Component Matrix of MSD}

\begin{tabular}{|l|c|c|c|c|}
\hline \multirow{2}{*}{ MSD items } & \multicolumn{3}{c|}{ Component } \\
\cline { 2 - 5 } & $\mathbf{1}$ & $\mathbf{2}$ & $\mathbf{3}$ & $\mathbf{4}$ \\
\hline Functions well integrated. & .663 & & & \\
\hline Problems are solved easily. & .740 & & & \\
\hline Functional coordination. & .778 & & & \\
\hline Business strategy. & .721 & & & \\
\hline Strategic planning process & & .820 & & \\
\hline Put strategic plan in writing. & & .809 & & \\
\hline Review and update & & .845 & & \\
\hline informal strategy & & .803 & & \\
\hline Pursue manufacturing strategy & & & .768 & \\
\hline Translated business strategy. & & & .772 & \\
\hline Potential manufacturing investments. & & & .789 & \\
\hline Manufacturing strategy is kept in business strategy & & & .738 & \\
\hline Awareness of business strategy. & & .786 & & \\
\hline Corporate decisions. & & & & .548 \\
\hline Long-range programs. & & & & .850 \\
\hline Manufacturing practices & & & & \\
\hline Technology in the industry. & & & & \\
\hline Next generation technology. & & & \\
\hline $\begin{array}{l}\text { Extraction Method: Principal Component Analysis. Rotation converged in } 6 \text { iterations } \\
\text { MSD: Manufacturing Strategy Dimensions }\end{array}$ & & & & \\
\hline
\end{tabular}


Table 6: Rotated Component Matrix of JIT

\begin{tabular}{|l|c|}
\hline \multirow{2}{*}{\multicolumn{1}{|c|}{ JIT items }} & Component \\
\cline { 2 - 2 } & $\mathbf{1}$ \\
\hline working to lower setup times & .623 \\
\hline Converting to external time & .657 \\
\hline Setup times of equipment & .693 \\
\hline Crews practices & \\
\hline Training workers & .762 \\
\hline Seems hopelessly & .693 \\
\hline Filling the kanban containers & .756 \\
\hline Separate packaging & .792 \\
\hline production control & .788 \\
\hline kanban squares, containers or signals & .690 \\
\hline Production schedule & .669 \\
\hline Completed on time. & .705 \\
\hline Completed as planned. & .746 \\
\hline Building time & \\
\hline Extra slack time & \\
\hline Adhere to the schedule & \\
\hline Behind schedule & \\
\hline
\end{tabular}

JIT: Just in Time 


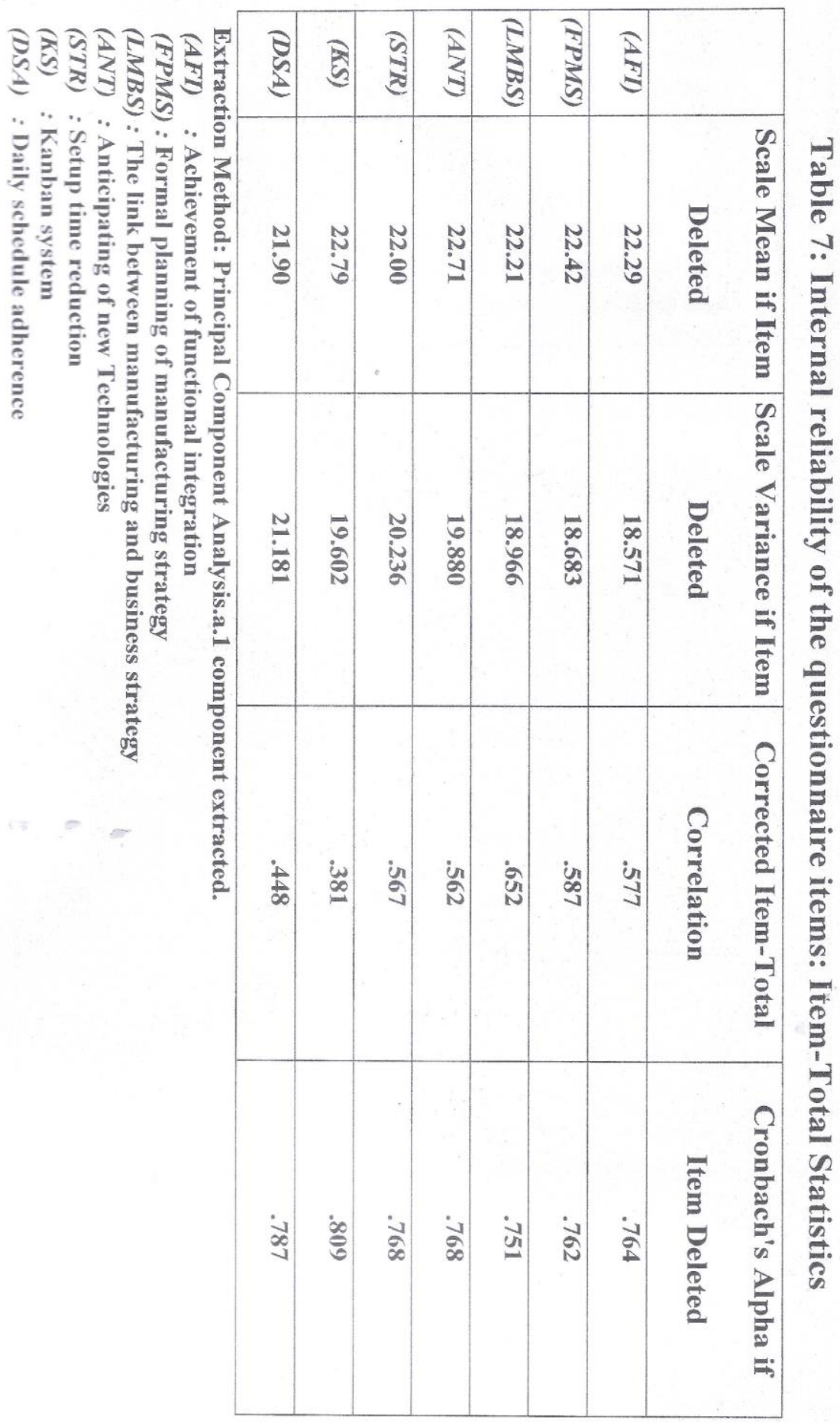




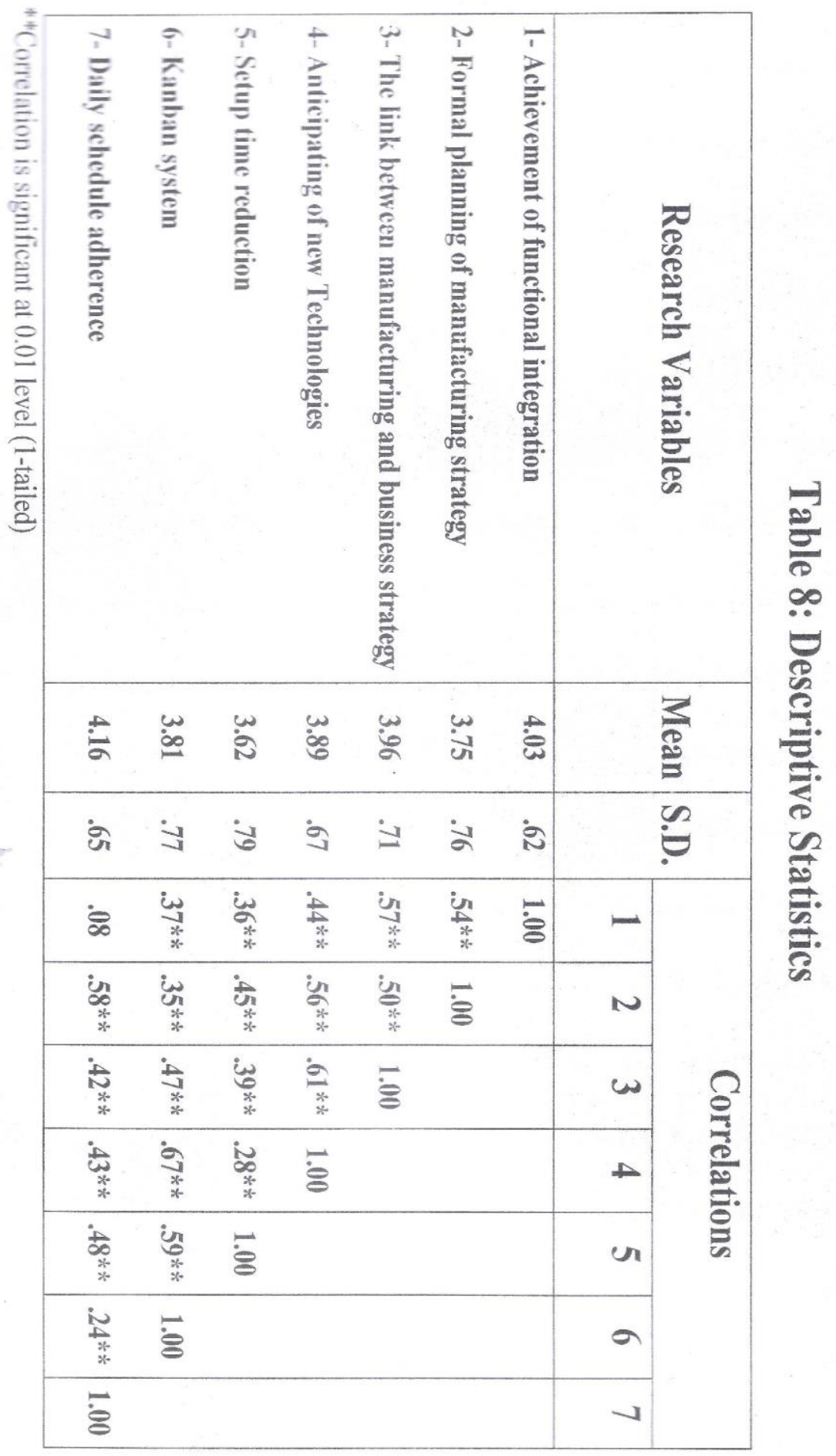


Table 9: Summary of Regression analyses (Model 1)

\begin{tabular}{|l|c|c|}
\hline \multicolumn{1}{|c|}{ Variables } & $\boldsymbol{\beta}$ & t value \\
\hline Achievement of functional integration & $.48^{* *}$ & 7.127 \\
Formal planning of manufacturing strategy & $.41^{* *}$ & 3.175 \\
The link between manufacturing and business strategy & $.43^{* *}$ & 5.157 \\
Anticipating of new technology & $.32^{* *}$ & 2.591 \\
\hline F value $=32.274^{* *}$ & & \\
Adjusted $R^{2}$ value $=.53$ & & \\
\hline
\end{tabular}

Notes: dependent variable: setup time reduction; $* * \mathrm{p}<.01$

\section{Table 10: Summary of Regression analyses (Model 2)}

\begin{tabular}{|l|c|c|}
\hline \multicolumn{1}{|c|}{ variables } & $\boldsymbol{\beta}$ & t value \\
\hline Achievement of functional integration & $.28^{* * *}$ & 4.203 \\
Formal planning of manufacturing strategy & .18 & 1.022 \\
The link between manufacturing and business strategy & $.35^{* *}$ & 4.599 \\
Anticipating of new technology & $.33^{* *}$ & 3.794 \\
\hline$F$ value $=18.412^{* *}$ & & \\
Adjusted $R^{2}$ value=.31 & & \\
\hline
\end{tabular}

Notes: dependent variable: Kanban system; $* * \mathrm{p}<.01$

Table 11: Summary of Regression analyses (Model 3)

\begin{tabular}{|l|c|c|}
\hline \multicolumn{1}{|c|}{ variables } & $\boldsymbol{\beta}$ & $\mathbf{t}$ value \\
\hline Achievement of functional integration & $.44^{* *}$ & 7.382 \\
Formal planning of manufacturing strategy & .12 & 1.051 \\
The link between manufacturing and business strategy & .19 & 1.193 \\
Anticipating of new technology & $.42^{* *}$ & 6.135 \\
\hline F value $=27.468^{* *}$ & & \\
Adjusted $R^{2}$ value $=.44$ & & \\
\hline
\end{tabular}

Notes: dependent variable: Daily schedule adherence; **p<.01 


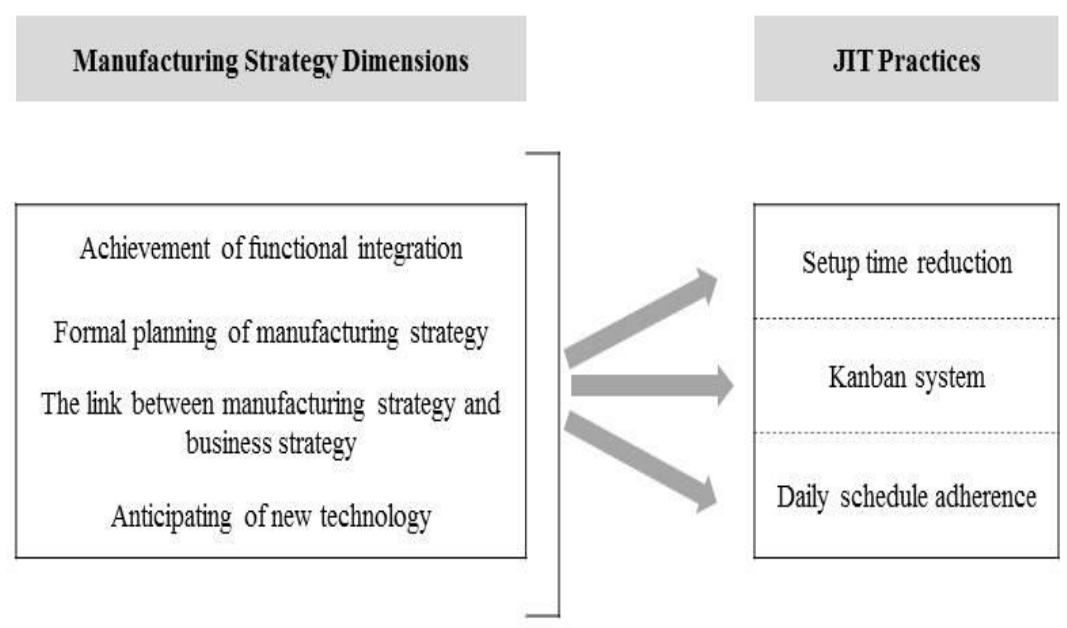

Source: Abdallah et al.(2007)

Figure 1: Manufacturing strategy Dimensions and JIT Practices 